\title{
Caracterización clínica, tomográfica, función respiratoria y pruebas de laboratorio de pacientes con diagnóstico de SARS-CoV-2
}

Clinical characterization, tomographic, respiratory function and laboratory tests of patients with a diagnosis of SARS-CoV-2 ypercoagulability status and thromboembolic complications in patients with SARS-CoV-2 infection

Recibido: 21/06/2021 Aceptado: 25/07/2021
Rocío María Celeste Sipaque De León

Universidad de San Carlos de Guatemala

rociisdl@gmail.com

https://orcid.org/0000-0003-2108-1236

\section{Referencia del artículo}

Sipaque De León, R. M. C. (2021). Caracterización clínica, tomográfica, función respiratoria y pruebas de laboratorio de pacientes con diagnóstico de SARS-CoV-2. Revista Diversidad Científica, 1(1),

25-33. DOl: https://doi.org/10.36314/diversidad.v1i1.4

\section{Resumen}

OBJETIVO: describir las características clínicas, tomográficas, función respiratoria y pruebas de laboratorio de los pacientes con diagnóstico de SARS-CoV-2. MÉTODO: estudio descriptivo retrospectivo de los pacientes ingresados al servicio del área respiratoria en el Centro Médico y Hospital El Pilar de Guatemala con diagnóstico de Sars-COV-2 durante los meses de junio de 2020 a marzo del 2021, con una muestra de 61 personas evaluadas. RESULTADOS: de 61 expedientes revisados con diagnóstico SARS-CoV-2 de los cuales, el sexo más afectado fue masculino con un $75 \%$ (46 pacientes) y el sexo femenino $25 \%$ ( 15 pacientes), el grupo etario más afectado fueron las personas de $46-55$ años con un 33\% (20 pacientes). La tres manifestaciones clínicas más frecuentes fue disnea con un $75 \%$ (46 pacientes) seguido de fiebre en un 67\% (41 pacientes), tos en un 66\% (40 pacientes), y en los hallazgos tomográficos tuvo predominio el patrón vidrio esmerilado 47\% (29 pacientes), seguido de un patrón alveolar difuso con un 26\% (16 pacientes), consolidación $23 \%$ (14 pacientes), con frecuente afectación bilateral en un $70 \%$ (43 pacientes). CONCLUSIÓN: Ios pacientes recuperados por diagnóstico de SARS-CoV-2 mostraron una función respiratoria alterada. Las pruebas de función respiratoria que fueron afectadas fue el patrón espirométrico sugerente a restricción con un $41 \%$ (25 pacientes), una difusión de monóxido de carbono con disminución el $26 \%$ (13 pacientes) y una restricción pulmonar en la pletismografía $20 \%$ (9 pacientes). 
Palabras clave: diagnóstico Sars-COV-2, función respiratoria, caracterización clínica

\begin{abstract}
OBJECTIVE: to describe the clinical, tomographic characteristics, respiratory function and laboratory tests of patients with a diagnosis of SARS-CoV-2. METHOD: retrospective descriptive study of patients admitted to the respiratory area service at the El Pilar Medical Center and Hospital in Guatemala with a diagnosis of Sars-COV-2 during the months of June 2020 to March 2021, with a sample of 61 people evaluated. RESULTS: of the 61 records reviewed with a SARS-CoV-2 diagnosis, of which the most affected sex was male with $75 \%$ (46 patients) and the female sex $25 \%$ ( 15 patients), the age group most affected were 46 people -55 years with $33 \%$ (20 patients). The three most frequent clinical manifestations were dyspnea with $75 \%$ (46 patients) followed by fever in $67 \%$ (41 patients), cough in 66\% (40 patients), and the ground glass pattern was predominant in the tomographic findings $47 \%$ (29 patients), followed by a diffuse alveolar pattern with $26 \%$ (16 patients), consolidation $23 \%$ (14 patients), with frequent bilateral involvement in 70\% (43 patients). CONCLUSION: the patients recovered by diagnosis of SARS-CoV-2 showed an altered respiratory function. The respiratory function tests that were affected were the spirometric pattern suggestive of restriction with $41 \%$ (25 patients), a diffusion of carbon monoxide with decrease in $26 \%$ (13 patients) and a pulmonary restriction in the plethysmography $20 \%$ (9 patients).
\end{abstract}

Keywords: sars-COV-2 diagnosis, respiratory function, clinical characterization 


\section{Introducción}

La causa de la enfermedad que se identificó mediante la tecnología de secuenciación del genoma como una nueva forma de coronavirus que se denominó síndrome respiratorio agudo severo coronavirus 2 (SARS-CoV-2) denominado coronavirus 2019 o COVID 19, inició a finales del 2019, a partir de casos de neumonía en Wuhan, China.

El brote de la enfermedad por coronavirus 2019 (COVID-19), fue declarado pandemia mundial en marzo de 2020. Este virus puede producir cuadros clínicos que van desde el resfriado común hasta otros más graves como los producidos por los virus del síndrome respiratorio agudo grave.

La pandemia por SARS-CoV-2 es uno de los desafíos más serios que ha enfrentado la humanidad en tiempos recientes. Ha cobrado en muy poco tiempo cientos de miles de vidas, infectando millones de personas, perturbado la economía mundial y causando miedo generalizado al futuro. Actualmente es una emergencia médica frecuente, que se asocia a una considerable alta tasa de morbilidad y mortalidad; siendo uno de los motivos más frecuentes de consulta y hospitalización, representando una importante carga económica y urgencia asistencial.

Con esta investigación se generó conocimientos de la enfermedad y su evolución pulmonar en el paciente con SARS-CoV-2, prestando especial atención en el comportamiento clínico del paciente, los hallazgos tanto de laboratorio como tomográfico, permite un adecuado diagnóstico del grado de alteración patológica respiratorio. Por lo tanto, surgió el interés de estudiar las características clínicas, epidemiológicas, tomográficos, función pulmonar y pruebas de laboratorio en pacientes que ingresaron al Centro Médico y al Hospital El Pilar de Guatemala con diagnóstico de SARS-CoV-2.

\section{Contenido \\ Epidemiología de la infección por SARS-CoV-2}

EI SARS-CoV-2 se replica principalmente en el tracto respiratorio superior e inferior y se transmite principalmente por gotitas de sujetos infectados asintomáticos y sintomáticos. La estimación del número de reproducción básico $(R)$ se encuentra actualmente entre 2 y 3 , mientras que el período de incubación es de 6 (mediana, rango 2-14) días. Aunque la mayoría de las infecciones no presentan complicaciones, entre el $5 \%$ y el $10 \%$ de los casos desarrollan neumonía, que puede pro- 
vocar hospitalización, insuficiencia respiratoria e insuficiencia multiorgánica. Los factores de riesgo para un curso complicado de la enfermedad incluyen edad, hipertensión, Enfermedad crónica cardiovascular y pulmonar e inmunodeficiencia. La tasa general de letalidad es del 1,4\%, y la tasa aumenta en la sexta década de la vida.

El factor más importante para la rápida propagación del virus es probablemente la replicación altamente activa en el tracto respiratorio superior, que también permite la infección por personas infectadas asintomáticamente a corta distancia o con una formación eficaz de aerosoles (por ejemplo, cantando en espacios estrechos). EI SARS, por otro lado, sólo puede transmitirse después de la aparición de los síntomas, ni la infección ni el sitio de replicación se encuentran en el tracto respiratorio superior.

La membrana viral contiene proteínas S, E y M, y la proteína de pico juega un papel funcional vital en la entrada del virus. El gen rep codifica la proteína no estructural y constituye aproximadamente dos tercios del genoma en el extremo 5'. En detalle, la proteína $S$ está a cargo de la unión al receptor y la entrada viral subsiguiente en las células huésped y, por lo tanto, es un objetivo terapéutico importante. Las proteínas $\mathrm{M}$ y $\mathrm{E}$ desempeñan funciones importantes en el ensamblaje viral y la proteína N es necesaria para la síntesis de ARN (Song, et al., 2019).

En los primeros estudios, el 49-66\% de los pacientes tenían antecedentes de contacto en el mercado de mariscos de Wuhan, donde se vendían varios tipos de animales salvajes vivos, incluidas aves de corral, murciélagos y marmotas. Actualmente se especula que el brote de COVID-19 en Wuhan está asociado con animales salvajes. Según la OMS, las muestras ambientales tomadas del mercado de productos del mar de Huanan dieron positivo al SARS-CoV-2 (Gralinski y Menachery, 2020) pero no se han identificado los animales específicos asociados con el virus.

Basado en evidencia previa, los murciélagos, el anfitrión de más de 30 coronavirus (División of clinical microbiology et al. 2020) puede ser el origen de COVID-19. El ciclo de vida del virus con el huésped consta de los siguientes 5 pasos: adhesión, penetración, biosíntesis, maduración y liberación. Una vez que los virus se unen a los receptores del hospedador mediante endocitosis o fusión de membranas (penetración), luego el contenido viral se libera dentro de las células huésped, el ARN viral ingresa al núcleo para su replicación. El ácido ribonucleico mensajero (ARNm) viral se usa para producir proteínas virales (biosíntesis). Luego, se producen (maduración) y se liberan nuevas partículas virales. 
Los coronavirus constan de cuatro proteínas estructurales; pico (S), membrana (M), envoltura (E) y nucleocápside (N) (Bosch et al. 2003). Spike está compuesto por una glicoproteína trimétrica transmembrana que sobresale de la superficie viral, lo que determina la diversidad de coronavirus y el tropismo del huésped. Spike comprende dos subunidades funcionales; la subunidad $\mathrm{S} 1$ es responsable de unirse al receptor de la célula huésped y la subunidad S2 es responsable de la fusión de las membranas viral y celular.

La enzima convertidora de angiotensina 2 (ACE2) se identificó como un receptor funcional para el SARS-CoV. El análisis estructural y funcional mostró que el pico de SARS-CoV-2 también se unió a ACE2. La expresión de ACE2 fue alta en pulmón, corazón, íleon, riñón y vejiga. En el pulmón, ACE2 se expresó en gran medida en las células epiteliales del pulmón ( $\mathrm{Li}$, et al. 2003).

\section{Interacción con el sistema inmunitario}

Debido a que la ACE2 se expresa en gran medida en el lado apical de las células epiteliales pulmonares en el espacio alveolar, es probable que el virus pueda entrar y destruirlas. La lesión pulmonar temprana se observó a menudo en la vía aérea distal. Las células epiteliales, los macrófagos alveolares y las células dendríticas (CD) son tres componentes principales de la inmunidad innata en las vías respiratorias.

Las células dendríticas residen debajo del epitelio. Los macrófagos se encuentran en el lado apical del epitelio. Las CD y los macrófagos actúan como células inmunitarias innatas para luchar contra los virus hasta que interviene la inmunidad adaptativa (Yuki et al. 2020).

Estas células presentadoras de antígeno se mueven hacia los ganglios linfáticos de drenaje para presentar antígenos virales a las células T. Las células T CD4+ y CD8+ juegan un papel fundamental. Las células T CD4+ se activan las células B para promover la producción de anticuerpos específicos del virus, mientras que las células $T$ CD8+ pueden matar las células infectadas por el virus.

Los pacientes con enfermedades graves mostraron linfopenia, en particular la reducción de las células $T$ de sangre periférica además presentando concentraciones plasmáticas aumentadas de citocinas proinflamatorias, incluyendo interleucina (IL)-6, IL-10, factor estimulante de colonias de granulocitos (GCSF) proteína qui- 
mioatrayente de monocitos 1 (MCP1), macrófagos inflamatorios proteína (MIP) $1 \alpha$ $y$ factor de necrosis tumoral (TNF) - $\alpha$ (Zhou et al., 2020).

Los síntomas de COVID-19 no son específicos y la presentación de la enfermedad puede variar desde ausencia de síntomas (asintomática) hasta neumonía grave y muerte. Al 20 de febrero de 2020 y según 55,924 casos confirmados por laboratorio, los signos y síntomas típicos incluyen: fiebre $(87.9 \%)$, tos seca $(67.7 \%)$, fatiga (38.1\%), producción de esputo (33.4\%), dificultad para respirar $(18.6 \%)$, dolor de garganta $(13.9 \%)$, dolor de cabeza $(13.9 \%)$, mialgias o altralgias $(14.8 \%)$, escalofríos $(11.4 \%)$, náuseas o vómitos $(5.0 \%)$, congestión nasal $(4.8 \%)$, diarrea $(3.7 \%)$, hemoptisis $(0.9 \%)$ y congestión conjuntival $(0.8 \%)$.

Las personas con COVID-19 generalmente desarrollan signos y síntomas, incluidos síntomas respiratorios leves y fiebre, en un promedio de 5-6 días después de la infección (período medio de incubación de 5 días, rango de 1-14 días) (OMS 2020).

La mayoría de las personas infectadas con el virus COVID-19 tienen una enfermedad leve y se recuperan. Aproximadamente el $80 \%$ de los pacientes confirmados por laboratorio han tenido una enfermedad leve a moderada, que incluye casos de neumonía y no neumonía, el 13,8\% tiene enfermedad grave (disnea, frecuencia respiratoria $\geq 30$ / minuto, saturación de oxígeno en sangre $\leq 93 \%$, relación $\mathrm{PaO} 2$ / $\mathrm{FiO} 2<300$, y / o infiltrados pulmonares $>50 \%$ del campo pulmonar en $24-48$ horas) y el $6,1 \%$ son críticos (insuficiencia respiratoria, choque séptico y / o disfunción / insuficiencia multiorgánica).

Se ha informado de infección asintomática, pero la mayoría de los casos relativamente raros que son asintomáticos en la fecha de identificación/notificación desarrollaron la enfermedad. La proporción de infecciones verdaderamente asintomáticas no está clara, pero parece ser relativamente rara y no parece ser un factor importante de transmisión (OMS, 2020).

\section{Conclusiones}

El estudio realizado en los hospitales Centro Médico y el hospital El Pilar tuvo un total de 61 expedientes revisados con diagnóstico SARS-CoV-2 de los cuales, el sexo más afectado fue masculino con un $75 \%$ (46 pacientes) y el sexo femenino $25 \%$ (15 pacientes), el grupo etario más afectado fueron las personas de 46-55 años con un $33 \%$ (20 pacientes). Las personas referidas fueron de la ciudad de Guatemala con un $92 \%$ (57 pacientes). 
La manifestación clínica más frecuente fue disnea con un 75\% (46 pacientes) seguido de fiebre en un 67\% (41 pacientes), tos en un 66\% (40 pacientes), malestar general en un 54\% (33 pacientes), fatiga con un 51\% (31 pacientes), con menos porcentaje se encontró odinofagia, cefalea, mialgias, rinorrea, anosmia, congestión nasal, diarrea, hipogeusia.

De acuerdo a los hallazgos tomográficos característicos de SARS-CoV-2 tiene predominio el patrón vidrio esmerilado $47 \%$ (29 pacientes), seguido de un patrón alveolar difuso con un 26\% (16 pacientes), consolidación 23\% (14 pacientes), con frecuente afectación bilateral en un 70\% (43 pacientes).

Los pacientes recuperados por diagnóstico de SARS-CoV-2 mostraron una función respiratoria alterada. Las pruebas de función respiratoria que fueron afectadas fue el patrón espirométrico sugerente a restricción con un $41 \%$ (25 pacientes), una difusión de monóxido de carbono con disminución el 26\% (13 pacientes) y una restricción pulmonar en la pletismografía 20\% (9 pacientes).

\section{Declaración}

El estudio se realizó con fines médicos, de acuerdo a las directrices de la Declaración de Helsinki y Código de Ética y Buenas Prácticas COPE, con las autorizaciones hospitalarias participantes en el estudio.

\section{Conflicto de intereses}

La autora declara no tener ningún conflicto de intereses.

\section{Referencias}

Bosch, B., Van der Zee, R., de Haan, CAM., Torrier, P. (2003). The coronavirus spike protein is a class I virus fusion protein: structural and functional characterization of the fusion core complex. Journal of virology $77(16)$. https://doi.org/10.1128/ JVI.77.16.8801-8811.2003

Division of Clinical Microbiology, University of Pittsburgh and University of Pittsburgh Medical Center. (2020). Novel coronavirus: from discovery to clinical 
diagnostics. Infection, genetics and evolution 79(1) https://doi.org/10.1016/j. meegid.2020.104211

Gralinski, L. \& Menachery, V. (2020). Return of the coronavirus: 2019-nCoV Viruses, 12(2). https://doi.org/10.3390/v12020135

Li, W., Moore, M., Vasilieva, N., Sul, J., Wong, S., Berne, M., Somasundaran, M., Sullivan, J., Luzuriaga, K., Greenough, T., Choe, H., Farzan, M. (2003). Nature 426(1). https://doi.org/10.1038/nature02145

Song, Z.; Xu, Y., Bao, L., Zhang, L., Yu, P., Qu, Y., Zhu, H., Zhao, W., Han, Y. \& Qin, C. (2019) . From SARS to MERS, thrusting coronaviruses into spotlight. Viruses 11(1). https://sci-hub.se/10.3390/v11010059

Yuki, K., Fujiogi, M., Koutsogiannaki, S. (2020). COVID-19 pathophysiology: a review. Clinical Immunology 215. https://doi.org/10.1016/j.clim.2020.108427

Zhou, Y., Fu, B., Zheng, X., Wang, D., Zhao, C., Qi, Y., Sun, R., Tian, Z., Xu, X., Wei, $H$. (2020). Pathogenic T cells and inflammatory monocytes incite inflammatory storm in serve COVID-19 patients. National Science Review 7(6). https://doi. org/10.1093/nsr/nwaa041

\section{Sobre la autora \\ Rocío María Celeste Sipaque De León}

Es estudiante de la carrera de médico y cirujano. Carrera de Médico y Cirujano, Centro Universitario de Oriente CUNORI, Facultad de Ciencias Médicas, Universidad de San Carlos de Guatemala. 
Copyright (c) Rocío María Celeste Sipaque De León

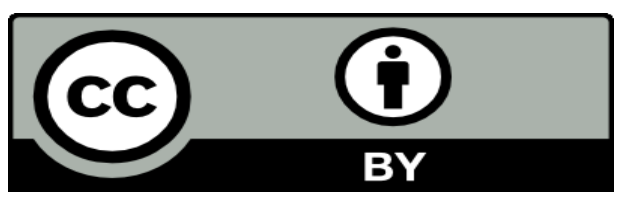

Este texto está protegido por una licencia CreativeCommons 4.0.

Usted es libre para compartir, copiar y redistribuir el material en cualquier medio o formato y adaptar el documento, remezclar, transformar y crear a partir del material para cualquier propósito, incluso comercialmente, siempre que cumpla la condición de atribución: usted debe reconocer el crédito de una obra de manera adecuada, proporcionar un enlace a la licencia, e indicar si se han realizado cambios. Puede hacerlo en cualquier forma razonable, pero no de forma tal que sugiera que tiene el apoyo del licenciante o lo recibe por el uso que hace. 